\title{
Temperament: an event-related potential study using the oddball paradigm
}

\author{
Boris V. Chernyshev ${ }^{1,2}$, Ivan E. Lazarev ${ }^{1}$, and Elena G. Chernysheva ${ }^{1}$ \\ 1. National Research University Higher School of Economics, Moscow, Russian Federation \\ 2. Lomonosov Moscow State University, Moscow, Russian Federation
}

\begin{abstract}
The present study examined the structure of interrelations between brain event-related potentials and behavioral measures and temperament dimensions during an attention task. Three temperament questionnaires were used: Eysenck Personality Inventory, Strelau Temperament Inventory, and Rusalov Structure of Temperament Questionnaire. Event-related potentials were recorded using the active auditory oddball paradigm. The stimuli $(85 \mathrm{~dB} ; 1050$ and $1000 \mathrm{~Hz}$ sinusoidal tones as targets and non-targets, respectively) were easily discriminated by all of the participants. A complex framework of interrelations between temperament and personality dimensions, behavioral measures, and event-related potentials was found. P3 amplitude was negatively correlated with the number of response omissions. Emotionality was positively correlated with P2 and N1-P2 complex amplitudes. Extraversion and Mobility of Nervous Processes were negatively correlated with the amplitude of the N1-P2 complex, and Social Ergonicity was negatively correlated with N2 latency. The results indicate that Extraversion tends to be associated with both the intensity and temporal aspects of temperament and suggest the importance of using a multidimensional approach in temperament studies. Keywords: temperament, personality, attention, electroencephalogram, event-related potentials.
\end{abstract}

Received 04 May 2013; received in revised form 05 August 2013; accepted 17 August 2013. Available online 23 December 2013.

\section{Introduction}

Temperament is often viewed as a set of genetically determined and stable biological characteristics that shape various aspects of behavior and mental processes (Eysenck, 1970; Gray, 1991; Costa, \& McCrae, 1995; Rusalov, 2002; Strelau, Mitina, Zawadzki, Babaeva, $\&$ Menchuk, 2005). The theories of temperament and personality stand on different methodological grounds, and questionnaires produced within their frameworks offer differing yet related sets of dimensions. The complex pattern of statistical ties between questionnaire dimensions and their dependence on characteristics of population samples were recently addressed in several

Boris Vladimirovich Chernyshev, National Research University Higher School of Economics, Psychophysiology, Vogogradskiy prosp., 46 b, Moscow 109316, Russian Federation, and Lomonosov Moscow State University, Higher Nervous Activity, Leninskiye Gory d.1, str.12, Faculty of Biology, Moscow 119234, Russian Federation. Ivan Evgenyevich Lazarev, and Elena Georgievna Chernysheva, National Research University Higher School of Economics, Psychophysiology, Moscow, Russian Federation. Correspondence regarding this article should be directed to: Boris Vladimirovich Chernyshev, National Research University Higher School of Economics, Psychology, Psychophysiology, Volgogradskiy prosp., 46 b Moscow 109316, Russian Federation. E-mail: bchernyshev@hse.ru publications (Chernyshev, Ramendik, Chernysheva, Bezsonova, \& Zinchenko, 2010; Ramendik, 2011).

Such an inter-theoretical analysis suggests that extraversion is correlated with both the intensity and temporal dimensions of temperament (Gray, 1991; Ilyin, 2004; Strelau et al., 2005; Golubeva, 2010), thus possibly not being a unitary dimension. Extraversion is a major constituent temperament dimension in several influential theories (Eysenck, 1970; Costa, \& McCrae, 1995). The important distinction between the intensity and temporal dimensions of temperament has roots in the physiological works of Pavlov (19511952) that inspired numerous psychological and psychophysiological temperament and personality theories, including those of Teplov (1964), Nebylitsyn (1972), Strelau et al. (2005), Rusalov (1989, 2002), and Golubeva (2005, 2010).

The latter theories of temperament (and personality in broader terms) partly have their roots in brain physiology, and recording brain activity in relation to temperament appears to be a valid way of searching for the brain events and processes that lie at the basis of temperament (Golubeva, 2005). Event-related potentials (ERPs) proved to be a very informative method for studying the brain correlates of psychological processes with a time resolution that far exceeds standard behavioral measures (Luck, 2005). Late ERP components (i.e., N1, $\mathrm{P} 2, \mathrm{~N} 2$, and P3) related to preattentional and attentional 
processes (Näätänen, 1992) appear to be the most relevant and most extensively investigated in relation to personality and temperament.

A greater body of this research was performed with a particular focus on the Extraversion dimension. In one of the first studies of this kind, which involved actively counting auditory stimuli (Stelmack, Achorn, \& Michaud, 1977), a higher amplitude of the N1-P2 complex was reported in introverts. The N1 amplitude was also found to be higher in introverts in a more recent report (Doucet, \& Stelmack, 2000). These findings are consistent with Eysenck's hypothesis of a higher level of cortical excitation in introverts. In a situation of passively listening to stimuli of various intensities, the amplitude of the P2-N2 complex was found to be higher in extraverts (Friedman, \& Meares, 1979). Golding, \& Richards (1985) did not find any significant correlations between Extraversion and visual ERP parameters.

Researchers who studied the relationships between Extraversion and P3 amplitude obtained controversial results. Some studies reported that higher Extraversion corresponds to a higher P3 amplitude (Gurrera, Salisbury, O’Donnell, Nestor, \& McCarley, 2005; Philipova, 2008; Gurrera, O’Donnell, Nestor, Gainski, \& McCarley, 2001; Fishman, Ng, \& Bellugi, 2011; Cahill, \& Polich, 1992), whereas other studies reported that higher Extraversion corresponds to a lower P3 amplitude (Daruna, Karrer, \& Rosen, 1985; Tatalović Vorkapić, 2009; Beauducel, Brocke, \& Leue, 2006; Hansenne, 2000; Wilson, \& Languis, 1990) or failed to find any influence of Extraversion on P3 amplitude (Camposano, Alvarez, \& Lolas, 1994). The relationship between Extraversion and P3 peak latency is also ambiguous. Some studies revealed that higher Extraversion accompanies a later P3 peak (Stelmack, Houlihan, \& McGarry-Roberts, 1993). Other authors suggested that a person who is more extraverted will have an earlier P3 peak (Tatalović Vorkapić, 2009; Camposano et al., 1994; Rammsayer, \& Stahl, 2004). A viable explanation for such discrepancies comes from the report by Ditraglia, \& Polich (1991), who demonstrated that P3 amplitude habituated faster in extraverts, thus making the amplitude dependent on the duration of the experiment and other secondary factors.

Compared with Extraversion, the relationships between other psychometric dimensions and ERPs have been much less studied. The N1 peak and N1P2 complex were found to be related not only to Extraversion but also to such dimensions as Sensationseeking and Neuroticism (Doucet, \& Stelmack, 2000; Hegerl, Gallinat, \& Mrowinski, 1995; Philipova, 2008). In a Go/No-Go task, N2 amplitude was positively correlated with anxiety (Righi, Mecacci, \& Viggiano, 2009). In the oddball task, P3 amplitude was found to negatively correlate with Neuroticism (Gurrera et al., 2005), although other authors found no difference in P3 amplitude between highly neurotic and highly stable people (Fjell, Walhovd, Meling, \& Johansen, 2005).

The aim of the present study was to determine the patterns of relationships between ERPs, temperament dimensions, and behavioral measures of attentional performance. In most studies of the relationships between temperament and brain activity reviewed above, a single questionnaire was used that was related to a single electrophysiological measure of interest. We suggest that a broader approach may be more fruitful in the search for the neurobiological basis of temperament.

In the present study, we used three temperament questionnaires based on different theories, and we analyzed all characteristic ERP peaks that are typical of the auditory oddball task. We tested the hypothesis that the three different temperament questionnaires are not only directly interrelated but also interrelated with behavioral and ERP data during subjects' performance in the oddball paradigm. By analyzing the entire set of questionnaires, behavioral data, and ERP data, we sought to describe the set of correlates of temperament dimensions and ERP and behavioral data. We particularly aimed to find psychophysiological evidence to view Extraversion as a compound dimension with both intensity and temporal characteristics.

\section{Methods}

\section{Participants}

Thirty university students, aged 18-27 years (20 females and 10 males, including 26 righthanded subjects, one left-handed subject, and three ambidextrous subjects), were enrolled in the study. All of the participants reported that they had normal hearing and no history of auditory, neurological, or mental illness. All of the procedures were approved by the local ethics committee, and written informed consent was obtained from all of the participants prior to the study.

\section{Apparatus}

Questionnaires. Three questionnaires were administered on the day of the experiment: Eysenck Personality Inventory (Eysenck, \& Eysenck, 1968; adapted in Russian by Shmelyov [2002]), Strelau Temperament Inventory (Strelau, Angleitner, \& Ruch, 1990; adapted in Russian by Danilova [1985]), and Structure of Temperament Questionnaire (Rusalov, 1989; Rusalov, 1990). The Eysenck Personality Inventory (EPI) consists of 57 questions, referring to personality dimensions of Extraversion (i.e., the need for external stimulation to support an optimal level of arousal; $\alpha=.67$ ) and Neuroticism (i.e., the tendency to experience negative emotional states; $\alpha=.81$ ). The Strelau Temperament Inventory (STI) contains 134 questions related to three basic properties of the nervous system: Strength of Excitation (i.e., the ability to endure arousing environmental influences; $\alpha=.82$ ), Strength of Inhibition (i.e., the ability to endure inhibiting environmental influences; $\alpha=.84$ ), and Mobility of Nervous Processes (i.e., the speed of alteration of excitation and inhibition processes; $\alpha=.81)$. The Structure of Temperament Questionnaire (STQ) includes 105 question that measure eight 
psychobiological properties of individual behavior in object-related and communicative spheres: Objectrelated Ergonicity (i.e., the disposition to perform mental and physical work; $\alpha=.83$ ), Social Ergonicity (i.e., the disposition to be involved in social activity; $\alpha=.76$ ), Object-related Plasticity (i.e., the ease of switching from one object-related activity to another; $\alpha=.77$ ), Social Plasticity (i.e., the ease of entering in social contacts and the diversity of communicative programs; $\alpha=.72$ ), Object-related Tempo (i.e., the speed of mental operations and motor acts in the process of objectrelated activity; $\alpha=.80$ ), Social Tempo (i.e., the speed of mental operations and motor acts in the process of communication; $\alpha=.73$ ), Object-related Emotionality (i.e., the emotional sensitivity to discrepancies between anticipated and real results of object-related activity; $\alpha=.84$ ), and Social Emotionality (i.e., the emotional sensitivity to failures in communication; $\alpha=.71$ ).

Electrophysiological recording and auditory stimulation. Electroencephalogram (EEG) was recorded using an NVX-52 system (Medical Computer Systems, Moscow, Russia) with Neocortex Pro software (Neurobotics, Moscow, Russia) from 32 electrodes in accordance with the $10-10 \%$ system and one electrooculogram electrode. Electrode impedance was kept below $10 \mathrm{k} \Omega$ for all of the channels. The electroencephalographic data were digitally recorded at a $2000 \mathrm{kHz}$ sampling rate. Auditory stimuli were presented using Neostimul software (Neurobotics, Moscow, Russia).

\section{Procedure}

Experimental settings. The experiments were performed in a quiet room where the participants were comfortably seated in an encephalographic chair. The stimuli were presented through loudspeakers. The stimuli were presented in quasirandom order according to the oddball paradigm, with a target-to-nontarget probability ratio of 1:4 (with no target stimuli presented in direct succession). The participants were instructed to press a button in response to the rare target stimulus. The target stimulus was a $1050 \mathrm{~Hz}$ tone, and the nontarget stimulus was $1000 \mathrm{~Hz}$. Both stimuli were pure sinusoidal tones. The duration of both stimuli was 40 $\mathrm{ms}$, with rise and fall times of $10 \mathrm{~ms}$ each. Loudness near the participant's head was approximately $85 \mathrm{~dB}$. The series included 250 stimuli (50 target stimuli and 200 non-target stimuli) with a random intertrial interval of $2,500 \pm 500 \mathrm{~ms}$.

Behavioral and ERP analysis. The behavioral outcome data of each trial could be one of the following: correct response to the target stimulus, false alarm to the non-target stimulus, response omissions, and correct rejections of the non-target stimulus. Mean latencies and latency dispersions (calculated as standard deviations) were obtained for each participant.

The ERP analysis reported herein was performed on 15 pericentral electrodes (F3, Fz, F4, Fc3, Fcz, Fc4, C3, Cz, C4, Cp3, Cpz, Cp4, P3, Pz, and P4).
Electroencephalogram artifacts were manually rejected, and electrooculographic artifacts were corrected with internal Neocortex Pro software based on the regression approach function. Evoked activity was calculated by coherent averaging the target trials. The zero line was adjusted separately for each record based on a prestimulus interval of $250 \mathrm{~ms}$ before stimulus onset.

Event-related potential peaks were manually marked in averaged ERP recordings in each electrode separately in the following time ranges: N1 (50-120 $\mathrm{ms})$, P2 (120-260 ms), N2 (190-310 ms), and P3 (250$530 \mathrm{~ms})$. Peak amplitudes and latencies were measured from the zero line and stimulus onset, respectively, in addition to the peak-to-peak measurement for the N1-P2 and N2-P3 complexes.

\section{Statistical analysis}

The statistical analyses of the ERP data and their relationships to the questionnaire data were performed using the general linear model (GLM). The questionnaire and behavioral data were separately analyzed as covariates, with the data from the 15 pericentral electrodes as the repeated measures.

Because the purpose of the present study was to explore the relationships between temperament and ERP measures and because a large number of data vectors were simultaneously analyzed, special caution was needed to preclude false-positive rejection of the null hypothesis because of the nature of multiple-hypothesis testing. With the purpose of additional statistical verification, each analysis that produced significant results was supplemented with a Spearman correlation between the averaged ERP parameters and behavioral/questionnaire data using bootstrapping analysis. All significant ERP data reported below were confirmed both by Spearman correlation and the bootstrapping procedure (Wu, 1986). The significance values reported below were produced by the GLM analysis. Correlation matrix statistics for questionnaire data were obtained using Spearman correlation. For illustrational purposes only, ERP data in the scatterplots are presented as averages across 15 pericentral electrodes for each participant separately, overlaid by corresponding regression lines.

\section{Results}

\section{Questionnaire data}

The correlation analyses of the questionnaire data produced multiple significant correlations between temperament dimensions (Table 1).

\section{Behavioral data and their relationships to questionnaire data}

As shown in Table 2, all of the participants successfully fulfilled the demands of the oddball task. Among the behavioral data, only the latency and within-participant latency dispersion were correlated with questionnaire data (Table 3). Social Ergonicity was positively correlated with the latency of correct 
Table 1. Correlation matrix of questionnaire data.

\begin{tabular}{|c|c|c|c|c|c|c|c|c|c|c|c|c|c|c|}
\hline & & $\begin{array}{l}\text { Mean } \\
(\mathrm{SD})\end{array}$ & 1 & 2 & 3 & 4 & 5 & 6 & 7 & 8 & 9 & 10 & 11 & 12 \\
\hline 1 & Extraversion & $58.7(22.7)$ & & & & & & & & & & & & \\
\hline 2 & Neuroticism & 46.8 (19.6) & .10 & & & & & & & & & & & \\
\hline 3 & $\begin{array}{l}\text { Strength of Excita- } \\
\text { tion }\end{array}$ & $68.8(9.8)$ & .23 & -.31 & & & & & & & & & & \\
\hline 4 & $\begin{array}{l}\text { Strength of Inhi- } \\
\text { bition }\end{array}$ & $72.4(10.7)$ & -.33 & .07 & -.03 & & & & & & & & & \\
\hline 5 & $\begin{array}{l}\text { Mobility of Nervous } \\
\text { Processes }\end{array}$ & $71.4(11.1)$ & $.62^{\star * *}$ & .10 & .47 & -.22 & & & & & & & & \\
\hline 6 & $\begin{array}{l}\text { Object-related } \\
\text { Ergonicity }\end{array}$ & $6.8(3.4)$ & -.08 & -.19 & $.46^{*}$ & .08 & .17 & & & & & & & \\
\hline 7 & Social Ergonicity & $8.5(3.4)$ & $.51^{\star *}$ & -.12 & .03 & -.13 & .26 & .23 & & & & & & \\
\hline 8 & $\begin{array}{l}\text { Object-related } \\
\text { Plasticity }\end{array}$ & $8.2(3.2)$ & .25 & -.03 & .35 & -.32 & $.49^{\star *}$ & .36 & .32 & & & & & \\
\hline 9 & Social Plasticity & $6.4(3.0)$ & $.62^{* * *}$ & -.06 & .26 & $-.56^{* * *}$ & .33 & -.13 & $.48^{* *}$ & $.41^{*}$ & & & & \\
\hline 10 & $\begin{array}{l}\text { Object-related } \\
\text { Tempo }\end{array}$ & $8.4(3.1)$ & $.50^{* *}$ & -.09 & .27 & -.28 & $.50^{* *}$ & .26 & $.43^{*}$ & $.44^{*}$ & .31 & & & \\
\hline 11 & Social Tempo & $9.2(3.0)$ & $.49^{* *}$ & -.01 & .25 & $-.39 *$ & $.48^{* *}$ & .10 & .31 & $.52^{\star *}$ & $.65^{* * *}$ & $.56^{* *}$ & & \\
\hline 12 & $\begin{array}{l}\text { Object-related } \\
\text { Emotionality }\end{array}$ & $6.2(4.1)$ & -.26 & $.63^{* * *}$ & -.26 & .14 & -.13 & .17 & -.05 & .04 & -.14 & -.21 & -.12 & \\
\hline 13 & Social Emotionality & $7.0(2.9)$ & -.26 & $.71^{* * *}$ & -.25 & .12 & -.13 & .22 & -.12 & -.07 & -.24 & -.04 & -.10 & $.78^{* * *}$ \\
\hline
\end{tabular}

$* p<.05, * * p<.01, * * * p<0.001$ (Spearman correlation).

Table 2. Behavioral data: percentage of false alarms, response omissions, response latency, and deviation of response latencies.

\begin{tabular}{llllll}
\hline & Mean & Median & Minimum & Maximum & SD \\
\hline False alarms (\% of non-target stimuli) & .27 & .00 & .00 & 1.50 & .50 \\
Response omissions (\% of target stimuli) & 4.73 & 2.00 & .00 & 22.00 & 6.16 \\
Response latency (ms) & 725.8 & 613.0 & 283.0 & 1663.0 & 356.5 \\
Deviation of response latencies (ms) & 22.9 & 19.7 & 13.4 & 38.6 & 7.4 \\
\hline
\end{tabular}

For false alarms and response omissions, the percentage was calculated relative to the number of corresponding stimuli in the experiment (200 non-target stimuli and 50 target stimuli).

Table 3. Correlation matrix between questionnaire data and behavioral data (Spearman $R$ ).

\begin{tabular}{|c|c|c|c|c|}
\hline & $\begin{array}{l}\text { False } \\
\text { alarms }\end{array}$ & Response omissions & $\begin{array}{l}\text { Mean } \\
\text { response } \\
\text { latency }\end{array}$ & Dispersion of response latencies \\
\hline Extraversion & .05 & .10 & .17 & -.17 \\
\hline Neuroticism & -.05 & -.30 & .07 & -.02 \\
\hline Strength of Excitation & .09 & .04 & -.24 & -.15 \\
\hline Strength of Inhibition & .27 & -.25 & -.25 & -.01 \\
\hline Mobility of Nervous Processes & -.04 & -.25 & .12 & $-.47^{\star *}$ \\
\hline Object-related Ergonicity & .17 & -.10 & -.04 & -.35 \\
\hline Social Ergonicity & -.02 & .07 & $.41^{*}$ & $-.39^{*}$ \\
\hline Object-related Plasticity & -.33 & -.21 & .33 & $-.43^{\star}$ \\
\hline Social Plasticity & -.12 & .20 & .11 & -.10 \\
\hline Object-related Tempo & .03 & -.08 & .13 & -.20 \\
\hline Social Tempo & -.12 & .05 & .04 & -.11 \\
\hline Object-related Emotionality & .00 & -.15 & .20 & -.14 \\
\hline Social Emotionality & .11 & -.23 & -.01 & -.07 \\
\hline
\end{tabular}


responses $(\mathrm{R}=.41, \mathrm{p}=.03)$. This same temperament dimension was negatively correlated with latency dispersion $(\mathrm{R}=-.39, \mathrm{p}=.03)$. Thus, higher Social Ergonicity was associated with later but more stable correct responses over time.

Two temporal dimensions of temperament-Mobility of Nervous Processes and Object-related Plasticity-were negatively correlated with latency dispersion $(R=-.47$, $p=.009$, and $R=-.43, p=.02$, respectively). Thus, higher Mobility of Nervous Processes and Object-related Plasticity were associated with more stable latencies of correct responses within participants.

\section{ERP parameters}

The ERP grand means in response to target stimuli and ERP scalp maps are shown in Figure 1. As shown in Figure 1, all of the peaks and peak complexes had almost a symmetrical frontocentral distribution, with amplitude maximums at Fz (N2), Fcz (N1, N1-P2, P3, N2-P3), and $\mathrm{Cz}(\mathrm{P} 2)$. Thus, all of the waves and wave complexes had a maximum or near-maximum amplitude at Fcz. The ERP grand mean waveform and scalp maps are presented in Figure 1.

A

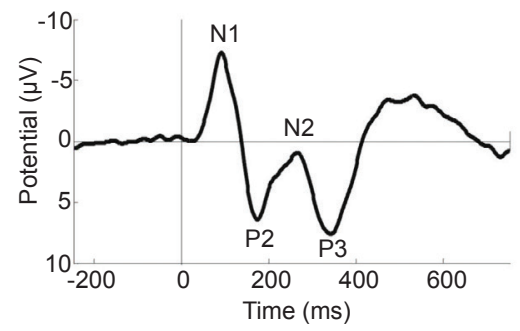

B

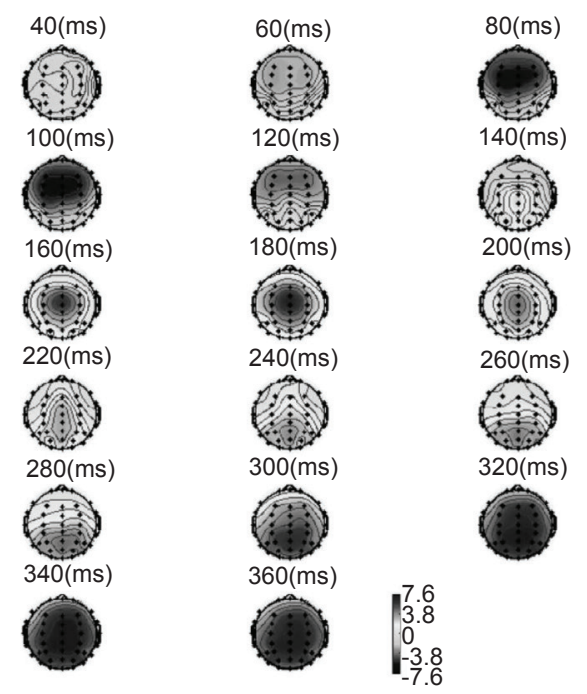

Figure 1. ERP grand mean $(\mathrm{N}=30)$. (A) ERP grand mean recorded at Fz. (B) ERP scalp maps at $40-360 \mathrm{~ms}$, showing N1, P2, N2 and P3. Scale: uV.

Relationships between ERP parameters and behavioral and questionnaire data

The number of response omissions to the target stimulus was negatively related to P3 amplitude
$\left(F_{1,28}=7.99, p=.009 ; R_{28}=-.51, p=.004\right.$; Figure 2A). A higher frequency of the participants' erroneously missing the response to the target stimulus was associated with a less-pronounced P3 wave, whereas good attentive performance was associated with higher P3 amplitude (Figure 3A).
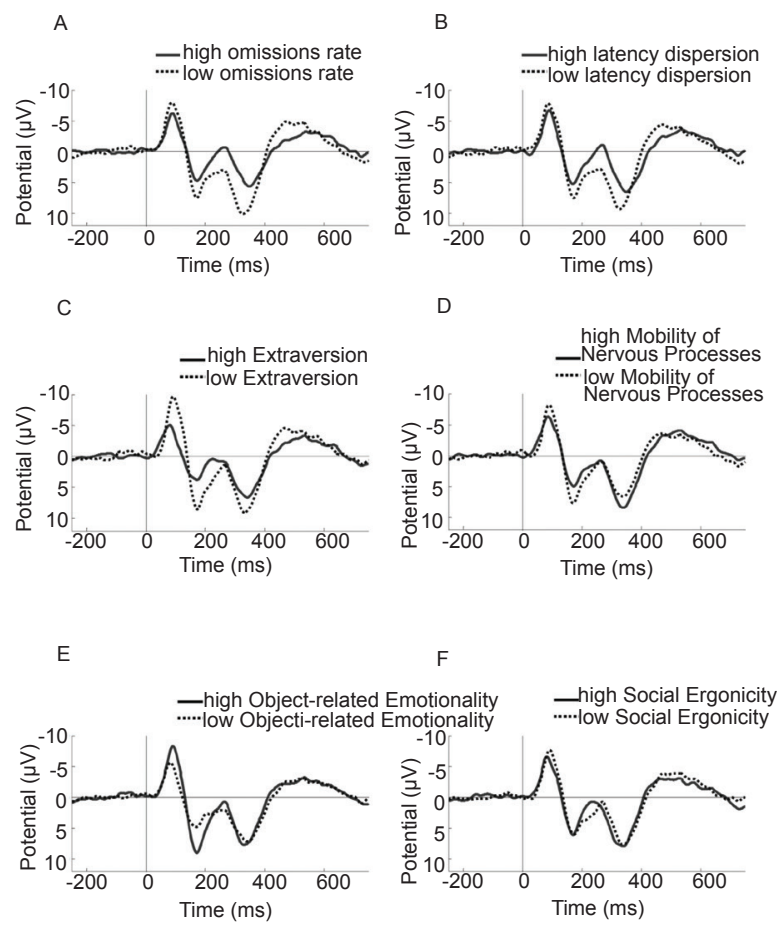

$\mathrm{F}$

Figure 2. ERP grand means recorded at Fcz in 30 participants divided in two groups accordin to the medians the following behavioral and questionnaire scores $(n=15$ in each subgroup). (A) Percentage of response omissions, (B) Dispersion of response latencies, (C) Extraversion, (D) Mobility of nervous processes, (E) Object-related emotionality, (F) Social ergonicity.

The dispersion of latencies was related to three ERP parameters (Figure 2B). First, the latency dispersion was negatively linked to $\mathrm{N} 2$ amplitude $\left(F_{1,28}=7.70\right.$, $p=.01 ; R_{28}=-.43, p=.02$ ). A more negative (i.e., more pronounced in absolute amplitude) N2 peak was associated with a greater latency dispersion (Figure 3B). Stable responses were more likely to be observed in individuals with a poorly manifested N2 peak. Second, the latency dispersion was positively linked to N2 latency $\left(F_{1,28}=6.30, p=.02 ; R=.48, p=.007\right.$; Figure 3C). Third, the latency dispersion was positively linked to P3 latency $\left(F_{1,28}=5.86, p=.02 ; R=.44, p=.01\right.$; Figure $3 \mathrm{D})$. Thus, later N2 and P3 peaks were associated with greater response latency dispersion. Stable responses were most often observed in individuals whose N2 peak was early and small and the P3 peak was early.

None of the behavioral data were significantly related to $\mathrm{N} 1$ and $\mathrm{P} 2$ peaks.

Two temperament questionnaire dimensionsExtraversion and Mobility of Nervous Processes-were negatively related to the amplitude of the N1-P2 complex 

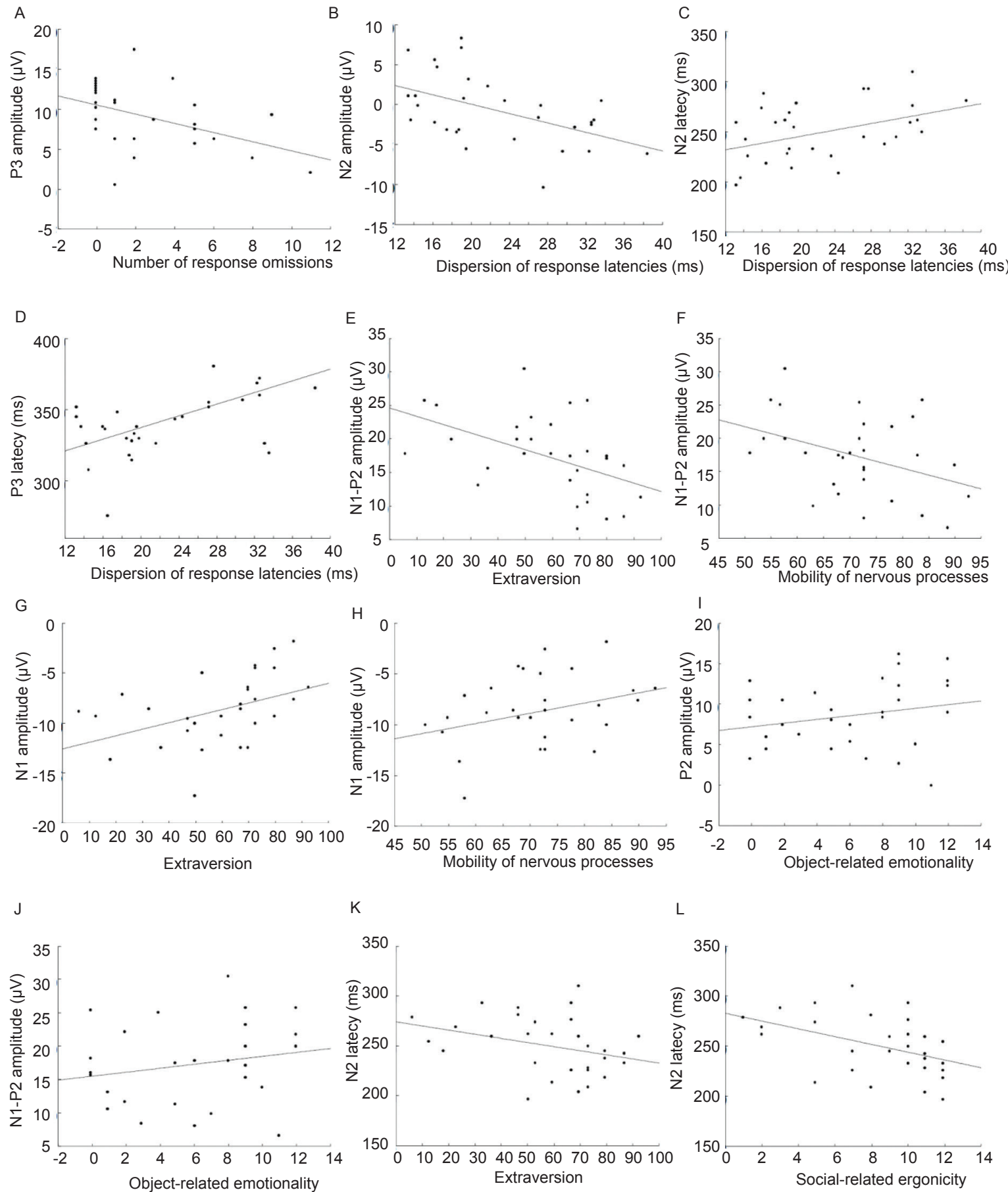

Figure 3. Scatterplots and regression lines of behavioral and ERP data vs. ERP parameters $(\mathrm{N}=30)$.

(Extraversion: $F_{1,28}=8.80, p=.006 ; R=-.53, p=.003$; Mobility of Nervous Processes: $F_{1,28}=8.50, p=.007$, $R=-.44, p=.02$; Figure $2 \mathrm{C}$ and $\mathrm{D}$ ). Higher individual Extraversion and Mobility of Nervous Processes were associated with a smaller N1-P2 complex (Figure 3E and $\mathrm{F}$ ).

Of the N1-P2 complex constituents, only the N1 amplitude was significantly related to Extraversion $\left(F_{1,28}=4.96, p=.03 ; R=.46, p=.01 ;\right.$ Figure $\left.3 \mathrm{G}\right)$ and Mobility of Nervous Processes $\left(F_{1,28}=6.50, p=.02\right.$; $R=.37, p=.04$; Figure $3 \mathrm{H}$ ).
As shown in Figure 2C, the P3 wave had an apparently greater amplitude in participants with low Extraversion compared with participants with high Extraversion, but the statistical analysis did not confirm this observation.

Object-related Emotionality was positively related to two ERP parameters: P2 amplitude $\left(F_{1,28}=7.72\right.$, $p=.01 ; R=.46, p=.01)$ and the amplitude of the N1P2 complex $\left(F_{1,28}=7.68, p=.01 ; R=.48, p=.007\right.$; Figure 2E). Thus, higher Object-related Emotionality was associated with more pronounced P2 and N1-P2 
complex amplitudes (Figure 3I and J). The N1 peak was seemingly unrelated to Emotionality.

Other temperament dimensions that were correlated with Object-related Emotionality (i.e., namely Neuroticism and Social Emotionality) did not produce verified significance in this analysis. Neuroticism was very far from significance and thus appeared to be completely unrelated to P2 and N1-P2 complex amplitudes. Social Emotionality was significantly related to the amplitude of the N1P2 complex in the GLM analysis $\left(F_{1,28}=5.19, p=.03\right.$; $R=.47, p=.008)$, but the significance of this association was not confirmed by the bootstrapping analysis.

Two temperament questionnaire dimensionsExtraversion and Social Ergonicity-showed a significant negative relationship to $\mathrm{N} 2$ latency (Extraversion: $F_{1,28}=6.93, p=.01 ; R=-.46, p=.01$; Social Ergonicity: $F_{1,28}=12.40, p=.001 ; R=-.55$, $p=.001$; Figure $2 \mathrm{C}$ and $\mathrm{F}$ ). Thus, higher Extraversion and Social Ergonicity were associated with a shorter N2 latency (Figure 3K and L).

\section{Discussion}

The present study combined two traditional research paradigms - ERP measurement during an oddball task and temperament questionnaires. This allowed us to find numerous significant interrelations between preattentional and attentional brain processes, reflected by ERPs and behavioral measures, and several temperament dimensions.

The questionnaire data and correlations between them generally agreed with reports by the authors of these questionnaires (Eysenck, 1970; Rusalov, 1997, 2002; Strelau et al., 2005), but some of the expected correlations were absent. This may have occurred because the validation studies mentioned above were performed in much larger samples.

According to our data, Extraversion was positively correlated not only with the social-related dimensions of Rusalov's questionnaire (i.e., Ergonicity, Plasticity, and Tempo; Rusalov, 1997) but also with a number of other dimensions, including Mobility of Nervous Processes and Object-related Tempo. No significant correlation was found between Extraversion and Strength of Excitation, in contrast to Strelau et al. (2005). Thus, although Extraversion reflects the quantity and quality of social communication, it also reflects some temporal aspects rather than intensity aspects of nervous system functioning.

Strength of Inhibition had fewer correlations with STQ dimensions than those reported by Rusalov (1997). According to Rusalov's report, Strength of Excitation was expected to correlate with Object-related Plasticity and Object-related Tempo, but such a correlation was not observed in the present study.

Generally, within our dataset, a block of temporal temperament characteristics was quite distinguishable and more prominent than intensity characteristics (i.e., strength), whereas the latter traditionally attracts more attention among psychophysiologists (Golubeva, 2005).
The behavioral data indicated that the oddball task was quite easy for all of the participants: nearly onethird of the participants did not commit a single error $(9$ of $30,30 \%$ ); others made almost a negligible number of errors of both kinds (i.e., response omissions and false alarms). Judging by very small latency dispersions, all of the participants had quite stable correct response latencies.

According to the present data, higher Social Ergonicity was associated with later but the more stable behavioral responses over time. Additionally, higher temporal dimensions of temperament (i.e., Mobility of Nervous Processes and Object-related Ergonicity) were associated with more stable behavioral responses over time.

The ERPs recorded in response to the target stimuli were quite typical of the oddball paradigm and other similar tasks (Ivanitsky, 1976; Rutman, 1979; Donchin, \& Coles, 1988; Näätänen, 1992; Gnezditskiy, 1997; Patel, \& Azzam, 2005; Polich, 2007). The N1-P2 complex was very clearly pronounced, with maximums at Fcz for $\mathrm{N} 1$ and $\mathrm{Cz}$ for $\mathrm{P} 2$.

The N2 amplitude reached a maximum at the most rostral electrodes in the analysis, which is typical of N2b and N2c components in tasks that involve auditory stimuli (Folstein, \& Van Petten, 2008; Patel, \& Azzam, 2005). The P3 wave was clearly apparent over frontoparietal electrodes and looked identical to classic P3b components (Näätänen, 1992; Polich, 2007; Rockstroh, 1982).

\section{Relationships between ERP parameters and behavioral and questionnaire data}

Behavioral data vs. ERP parameters. The behavioral data were found to be related to a number of ERP parameters. The P3 amplitude was negatively related to the number of response omissions (i.e., a greater P3 amplitude was associated with fewer omissions committed by the participants). Higher P3 amplitudes corresponded to better attentional performance (i.e., better reliability of stimulus detection and recognition). At the same time, P3 latency was unrelated to response latency.

The P3 wave is well known to be generated in response to significant stimuli (i.e., rare target stimuli in the oddball paradigm), and it is weak or absent in response to nonsignificant stimuli. In a pioneering study, Hillyard, Squires, Bauer, \& Lindsay (1971) reported smaller P3 waves for omissions in a situation of weak near-threshold signal detection, but the experimental task in the present study greatly differed from Hillyard et al. (1971). In the present study, the stimuli were easily discriminated by the participants. In our case, P3 was related to the effectiveness of target stimulus detection. According to Dehaene, \& Changeux (2011), P3b primarily reflects conscious processing. Stimuli of which the subject is unaware do not activate associative cortical areas and thus do not cause the generation of P3b. In many experiments (for a comprehensive review, 
see Dehaene, \& Changeux, 2011) being unaware of the stimuli was achieved either by presenting subthreshold stimuli or by experimental manipulations, such as masking or introducing a competing task. To our knowledge, the present data are the first demonstration of a spontaneous effect of this kind manifested at the between-subject level.

The absence of direct relationships between P3 latency and overt behavioral response latency has been documented in the literature, although P3 latency may depend on stimulus evaluation time (Magliero, Bashore, Coles, \& Donchin, 1984).

The dispersion of behavioral response latency (i.e., an inverted measure of response stability) was found to be related to three ERP parameters. Response latency was less stable in participants with greater N2. According to the literature, increased N2 amplitude can be observed under conditions of increased stimulus differentiation difficulty (Senkowski, \& Herrmann, 2002). N2 is also known to represent response inhibition processes in the Go/No-Go task (De Jong, Coles, Logan, \& Gratton, 1990). More pronounced N2 amplitude was also found in situations of conflict monitoring (Dickter, \& Bartholow, 2010; Kopp, Rist, \& Mattler, 1996). Thus, one can suppose that participants who had increased N2 amplitude faced greater subjective task difficulty or experienced a conflict while making their decision and consequently performed with less stable response latencies.

Additionally, behavioral response latency dispersion was positively related to N2 and P3 latencies. This means that the later generation of both cognitive components of ERP was associated with less stable response latencies. Presumably, the later generation of N2 and P3 indicates slower stimulus information processing (as if during a more difficult task). The P3 latency is known to correlate with task difficulty (Näätänen, 1992; Donchin, \& Coles, 1988; Rockstroh, 1982). Supposedly, individuals with unstable response latencies found the task to be more difficult. Because of this difficulty, N2 and P3 latencies increased, and N2 amplitude increased.

Thus, the stability of the behavioral response latency depended on N2 amplitude, N2 latency, and P3 latency. Notably, according to our data, N2 amplitude correlated with P3 latency, whereas N2 latency did not correlate with either ERP parameter.

Questionnaire data vs. ERP parameters. Three main results were obtained with regard to the relationships between ERP parameters and temperament dimensions. Fist, higher Extraversion and Mobility of Nervous Processes were associated with a smaller N1-P2 complex (i.e., the N1-P2 complex was higher in introverts than in extraverts). N1 exhibited a similar relationship to Mobility of Nervous Processes, but it was not as significant as the relationship between Extraversion and the N1-P2 complex. Apparently, although P2 itself was not involved in this effect, the entire N1-P2 complex played the most important role, and the amplitude of the complex appeared to be a more valid predictor of the aforementioned temperament dimensions than $\mathrm{N} 1$ alone. N1 amplitude was also found to be higher in introverts in the study by Doucet, \& Stelmack (2000), and the same result was previously reported for N1-P2 complex amplitude (Stelmack et al., 1977).

As described above, Extraversion and Mobility of Nervous Processes themselves were correlated. Thus, the fact that these dimensions appeared to be tied through a specific brain event suggests that Extraversion and Mobility of Nervous Processes may partially represent a facet of an as-yet-unknown temperament dimension. Notice that no such effect was observed for several other temperament dimensions measured in the present study, which were also correlated with Extraversion and Mobility of Nervous Processes. Other ERP measures did not present this effect. Thus, the interrelation between Extraversion and Mobility of Nervous Processes possibly lies in early brain processes within the N1-P2 time window.

One can speculate that some brain processes during the early preattentional stage of perception, manifested as the N1-P2 complex, require less brain resources in people with high Extraversion and high Mobility of Nervous Processes. Resource-effective early preattentional information processing may constitute the basis for an effective and fast attention allocation mechanism. Such individuals may process more stimuli at the preattentional stage at a given time and thus evaluate more potential future targets of attention before actually choosing the next relevant target and allocating attention to it. As a result, their attention can be switched faster to any new relevant target under real-world conditions. Therefore, this characteristic of attention may be partially detected by the Extraversion and Mobility of Nervous Processes dimensions of the questionnaires.

The data described above are consistent with Eysenck, \& Eysenck (1995), in which introverts experienced stronger excitation in response to external stimuli.

However, we did not confirm the results of Cahill, \& Polich (1992), who demonstrated that P3 was generally smaller for introverts than for extraverts, and Gurrera et al. (2005), who demonstrated a positive correlation between P3 amplitude with Extraversion. In Cahill, \& Polich (1992), only extreme introverts and extroverts were recorded, whereas participants in the present study often had intermediate Extraversion scores. P3 amplitude is also known to habituate more rapidly in extraverts than in introverts (Ditraglia, \& Polich, 1991), whereas no direct effect of Extraversion on P3 was found in that report. Thus, the nonsignificant tendency toward greater P3 in individuals with low Extraversion (introverts) in the present study can be explained by faster adaptation in extraverts.

Second, higher Object-related Emotionality was associated with a greater P2 and N1-P2 complex (which themselves are correlated). Social Emotionality exhibited the same tendency. This result seemingly 
and unexpectedly places Emotionality in opposition to Extraversion and Mobility of Nervous Processes. However, the difference is that the N1-P2 complex effect for Extraversion and Mobility of Nervous Processes was mostly attributable to variations in N1 amplitude, whereas it was mostly attributable to variations in P2 amplitude for Emotionality. Notice that the N1-P2 complex amplitude was strongly correlated with both $\mathrm{N} 1$ and $\mathrm{P} 2$, although the relationships with the questionnaire data clearly distinguished them. Greater resource allocation to preattentional processes, which manifest themselves as enhanced P2 and N1-P2 amplitudes, may lead to stronger emotional responses to stimuli in everyday life. No such effect was found for Neuroticism, which was strongly correlated with both aspects of Emotionality. Possibly some important differences in the authors' models of Neuroticism and Emotionality laid the basis of the two questionnaires. Notwithstanding the strong correlation between the two, these dimensions may be quite different, with Rusalov's Emotionality closer to the physiological basis of this phenomenon.

Third, higher Extraversion and Social Ergonicity were associated with a shorter N2 latency. Notably, these two temperament dimensions were positively correlated, and they may partially reflect the same unknown dimension of temperament in their positive relationship to N2 latency. Thus, this temperament characteristic that predisposes individuals to a greater quantity and intensity of social communication manifests itself as a shortened N2 latency. The latter may supposedly hint at the faster occurrence of some process at the moment of the transition from preattentive to attentive processing.

The dual nature of the Extraversion dimension. In the present study, we tested the hypothesis that the three different temperament questionnaires are not only directly interrelated but also interrelated with behavioral and ERP data in the oddball paradigm. We sought to describe the set of correlates of temperament dimensions with ERP and behavioral data. We particularly aimed to find psychophysiological grounds to view Extraversion as a compound dimension with both intensity and temporal characteristics.

Our results clearly showed that several temperament dimensions had a characteristic set of correlational ties with ERP peak parameters. Importantly, we found that Extraversion was indeed involved in two kinds of correlational ties that were pronounced at differing latencies after stimulus onset and hinted at both the intensity and temporal characteristics of temperament. Strelau (1982) performed a validation study of the Pavlovian Temperament Survey and found that Extraversion was positively correlated with both Strength of Excitation and Mobility of Nervous Processes. In later studies based on the regulative theory of temperament, Strelau et al. (2005) again demonstrated that Extraversion was correlated with both the intensity and temporal dimensions of temperament. Similar results were obtained in the studies that involved
Rusalov's Structure of Temperament Questionnaire (Rusalov, 1989, 1990). Attributions of Extraversion to the intensity or energetic side of psychic processing were also made in a number of psychophysiological studies (Ilyin, 2004; Golubeva, 2005; Beauducel et al., 2006). Golubeva (2005) used a psychophysiological photic EEG rhythm driving method and found that extraversion may have common manifestations with both the strength and mobility of the nervous system. Our study provided new evidence of such an understanding of Extraversion as a compound phenomenon and found relevant ties between temperament dimensions and ERP parameters.

\section{Conclusions}

The present results demonstrate that using several temperament and personality questionnaires simultaneously, together with behavioral measures and measures of brain activity, reveals a complex framework of interrelationships between these parameters, a fact that is generally consistent with a number of older and recent reports (Eysenck, 1970; Rusalov, 1997, 2002; Strelau et al., 2005; Chernyshev et al., 2010; Ramendik, 2011).

We found that Extraversion was related to different ERP parameters, each time in complex with another dimension. Together with Mobility of Nervous Processes, Extraversion was related to the amplitude of the N1-P2 complex. Together with Social Ergonicity, Extraversion was related to N2 latency. Thus, Extraversion manifests itself in two different ways - both as a temporal dimension and as an intensity dimension of temperament.

The results obtained in the present study provide hints about how one basic dimension of temperament and personality, Extraversion, may be related to two orthogonal dimensions of temperament and personality, formulated within a different theoretical framework. If we assume that each temperament dimension indirectly reflects some physiological property, then we have to assume that these properties may manifest themselves at different stages of information processing in the brain. The ERP method allowed us to study the progression of these processes over time and reveal the time-span of interplay between different dimensions of temperament and personality. This approach may provide a better understanding of the psychophysiological basis of temperament and personality.

In the present study, we also found relationships between behavioral measures and ERPs. The most important finding was that $\mathrm{P} 3$ amplitude was negatively related to the number of response omissions. This finding corroborated the current understanding of the role of P3 in conscious information processing (Dehaene, \& Changeux, 2011), but our data are the first direct demonstration of a between-subject effect.

\section{Acknowledgements}

The study was implemented in the framework of The Basic Research Program of the National Research 
University Higher School of Economics in 2011-2013. We thank Dr. Dina M. Ramendik, Evgenia S. Osokina, and Viktoria E. Bezsonova for their valuable contributions to the research and preparation of the manuscript.

\section{References}

Beauducel, A., Brocke, B., \& Leue, A. (2006). Energetical bases of extraversion: effort, arousal, EEG, and performance. International Journal of Psychophysiology, 62(2), 212-223.

Cahill, J. M., \& Polich, J. (1992). P300, probability, and introverted/ extroverted personality types. Biological Psychology, 33(1), 23-35.

Camposano, S., Alvarez, C., \& Lolas, F. (1994). Personality dimensions and cerebral evoked potential. Arquivos de NeuroPsiquiatria, 52(4), 489-492.

Chernyshev, B. V., Ramendik, D. M., Chernysheva, E. G., Bezsonova, V. E., \& Zinchenko, V. P. (2010). The specificity of temperament manifestation and its connection to auditory evoked potentials [in Russian]. Psychology. Journal of the Higher School of Economics, 7(3), 23-38.

Costa, P. T., \& McCrae, R. R. (1995). Domains and facets: hierarchical personality assessment using the revised NEO Personality Inventory. Journal of Personality Assessment, 64(1), 21-50.

Danilova, N. N. (1985). The functional states: mechanisms and diagnostics. Moscow: Izdatelstvo Moskovskogo Universiteta.

Daruna, J. H., Karrer, R., \& Rosen, A. J. (1985). Introversion, attention and the late positive component of event-related potentials. Biological Psychology, 20(4), 249-259.

De Jong, R., Coles, M. G., Logan, G. D., \& Gratton, G. (1990). In search of the point of no return: the control of response processes. Journal of Experimental Psychology: Human Perception and Performance, 16(1), 164-182.

Dehaene, S., \& Changeux, J. P. (2011). Experimental and theoretical approaches to conscious processing. Neuron, 70(2), 200-227.

Dickter, C. L., \& Bartholow, B. D. (2010). Ingroup categorization and response conflict: interactive effects of target race, flanker compatibility, and infrequency on N2 amplitude. Psychophysiology, 47(3), 596-601.

Ditraglia, G. M., \& Polich, J. (1991). P300 and introverted/extraverted personality types. Psychophysiology, 28(2), 177-184.

Donchin, E., \& Coles, M. G. (1988). Is the P300 component a manifestation of context updating? Behavioral and Brain Sciences, 11(3), 357-427.

Doucet, C., \& Stelmack, R. M. (2000). An event-related potential analysis of extraversion and individual differences in cognitive processing speed and response execution. Journal of Personality and Social Psychology, 78(5), 956-964.

Eysenck, H. J. (1970). The structure of human personality. London: Methuen.

Eysenck, H. J., \& Eysenck, M. W. (1995). Mindwatching: why we behave the way we do. London: Prion.

Eysenck, H. J., \& Eysenck, S. B. G. (1968). Manual for the Eysenck Personality Inventory. San Diego: Educational and Industrial Testing Service.

Fishman, I., Ng, R., \& Bellugi, U. (2011). Do extroverts process social stimuli differently from introverts? Cognitive Neuroscience, 2(2), 67-73.

Fjell, A. M., Walhovd, K. B., Meling, S., \& Johansen, M. B. (2005). Basic information processing of neurotics and stables: an experimental ERP approach to personality and distractibility. Scandinavian Journal of Psychology, 46(6), 493-502.

Folstein, J. R., \& Van Petten, C. (2008). Influence of cognitive control and mismatch on the N2 component of the ERP: a review. Psychophysiology, 45(1), 152-170.

Friedman, J., \& Meares, R. (1979). Cortical evoked potentials and extraversion. Psychosomatic Medicine, 41(4), 279-286.

Gnezditskiy, V. V. (1997). Evoked potentials in clinical practice [in Russian]. Taganrog: Izdatelstvo Taganrogskogo Gosudarstvennogo Universiteta.

Golding, J. F., \& Richards, M. (1985). EEG spectral analysis, visual evoked potential and photic-driving correlates of personality and memory. Personality and Individual Differences, 6(1), 67-76.
Golubeva, E. A. (2005). Capabilities. Personality. Individuality [in Russian]. Dubna: Feniks.

Golubeva, E. A. (2010). General and differential psychology: two-way influence of scientific schools of B.M. Teplov and E.N. Sokolov [in Russian]. Vestnik Moskovskogo Universiteta, 4, 32-56.

Gray, J. A. (1991). The neuropsychology of temperament. In J. Strelau, \& A. Angleitner (Eds.), Explorations in temperament: international perspectives on theory and measurement (pp. 105-128). London: Plenum Press.

Gurrera, R. J., O’Donnell, B. F., Nestor, P. G., Gainski, J., \& McCarley, R. W. (2001). The P3 auditory event-related brain potential indexes major personality traits. Biological Psychiatry, 49(11), 922-929.

Gurrera, R. J., Salisbury, D. F., O’Donnell, B. F., Nestor, P. G., \& McCarley, R. W. (2005). Auditory P3 indexes personality traits and cognitive function in healthy men and women. Psychiatry Research, 133(2-3), 215-228.

Hansenne, M. (2000). The p300 cognitive event-related potential: II. Individual variability and clinical application in psychopathology. Neurophysiologie Clinique, 30(4), 211-231.

Hegerl, U., Gallinat, J., \& Mrowinski, D. (1995). Sensory cortical processing and the biological basis of personality. Biological Psychiatry, 37(7), 467-472.

Hillyard, S. A., Squires, K. C., Bauer, J. W., \& Lindsay, P. H. (1971). Evoked potential correlates of auditory signal detection. Science, 172(3990), 1357-1360.

Ilyin, E. N. (2004). Psychology of individual differences [in Russian]. St. Petersbourg: Piter.

Ivanitsky, A. M. (1976). Brain mechanisms of signal evaluation [in Russian]. Moscow: Meditsina.

Kopp, B., Rist, F., \& Mattler, U. (1996). N200 in the flanker task as a neurobehavioral tool for investigating executive control. Psychophysiology, 33(3), 282-294.

Luck, S. (2005). An introduction to the event-related potential technique. Cambridge MA: MIT Press.

Magliero, A., Bashore, T. R., Coles, M. G., \& Donchin, E. (1984). On the dependence of $\mathrm{P} 300$ latency on stimulus evaluation processes. Psychophysiology, 21(2), 171-186.

Näätänen, R. (1992). Attention and brain function. Hillsdale, NJ: Lawrence Erlbaum.

Nebylitsyn, V. D. (1972). Fundamental properties of the human nervous system. New York: Plenum Press.

Patel, S. H., \& Azzam, P. N. (2005). Characterization of N200 and P300: selected studies of the event-related potential. International Journal of Medical Sciences, 2(4), 147-154.

Pavlov, I. P. (1951-1952). Complete works, 2nd ed [in Russian]. Moscow: SSSR Academy of Sciences.

Philipova, D. T. (2008). Changes in N1 and P3 components of the auditory event-related potentials in extroverts and introverts depending on the type of the task. Folia Medica, 50(2), 24-31.

Polich, J. (2007). Updating P300: an integrative theory of P3a and P3b. Clinical Neurophysiology, 118(10), 2128-2148.

Ramendik, D. M. (2011) Psychological markers of successfulness in the scientific work of biology students [in Russian]. Voprosy Obrazovaniya, 2011(1), 161-171.

Rammsayer, T., \& Stahl, J. (2004). Extraversion-related differences in response organization: evidence from lateralized readiness potentials. Biological Psychology, 66(1), 35-49.

Righi, S., Mecacci, L., \& Viggiano, M. P. (2009). Anxiety, cognitive self-evaluation and performance: ERP correlates. Journal of Anxiety Disorders, 23(8), 1132-1138.

Rockstroh, B. (1982). Slow Brain Potentials and Behavior. Baltimore: Urban \& Schwarzenberg.

Rusalov, V. M. (1989). Object-related and communicative aspects of human temperament: a new questionnaire of the structure of temperament. Personality and Individual Differences, 10(8), 817827.

Rusalov, V. M. (1990). Structure of Temperament Questionnaire [in Russian]. Moscow: Izdatelstvo IP AN SSSR.

Rusalov, V. M. (1997). Formal-dynamic properties of individuality questionnaire: workbook [in Russian]. Moscow: Izdatelstvo IP RAN.

Rusalov, V. M. (2002). Natural preconditions and individualpsychophysiological peculiarities of personality Psychology of 
Personality in Works of Russian Psychologists [in Russian]. St. Petersburg: Piter.

Rutman, E. M. (1979). Evoked potentials in psychology and psychophysiology [in Russian]. Moscow: Nauka.

Senkowski, D., \& Herrmann, C. S. (2002). Effects of task difficulty on evoked gamma activity and ERPs in a visual discrimination task. Clinical Neurophysiology, 113(11), 1742-1753.

Shmelyov, A. G. (2002). Psychodiagnostics of personal traits [in Russian]. St. Petersburg: Rech.

Stelmack, R. M., Achorn, E., \& Michaud, A. (1977). Extraversion and individual differences in auditory evoked response. Psychophysiology, 14(4), 368-374.

Stelmack, R. M., Houlihan, M., \& McGarry-Roberts, P. A. (1993). Personality, reaction time, and event-related potentials. Journal of Personality and Social Psychology, 65(2), 399-409.

Strelau, J. (1982). The role of temperament in psychic development [in Russian]. Moscow: Progress Publishers.

Strelau, J., Angleitner, A., \& Ruch, W. (1990). Strelau Temperament Inventory (STI): general review and studies based on German samples. In J.N. Butcher, \& C.D. Spielberger (Eds.), Advances in Personality Assessment, vol. 8 (pp. 187-241). Hillsdale, NJ: Lawrence Erlbaum.

Strelau, J., Mitina, O., Zawadzki, B., Babaeva, J., \& Menchuk, T. (2005). Methods of diagnostics of temperament (formal-dynamic characteristics of behavior) [in Russian]. Moscow: Smysl.

Tatalović Vorkapić, S. (2009). Biological correlates of P300 and extraversion relationship. Collegium Antropologicum, 33(4), 12151222.

Teplov, B. M. (1964). Problems in the study of general types of higher nervous activity in man and animals. In J.A. Gray (Ed.), Pavlov's typology: recent theoretical and experimental developments from the laboratory of B.M. Teplov (pp. 3-153). Oxford: Pergamon Press.

Wilson, M. A., \& Languis, M. L. (1990). A topographic study of differences in the P300 between introverts and extraverts. Brain Topography, 2(4), 269-274.

Wu, C. F. J. (1986). Jackknife, bootstrap and other resampling methods in regression analysis. Annals of Statistics, 14(4), 1261-1295. 